ANL-79-70

\title{
NUMERICAL METHOD FOR SOLUTION OF TRANSIENT, HOMOGENEOUS, EQUILIBRIUM, TWO-PHASE FLOWS IN ONE SPACE DIMENSION
}

by

Yong W. Shin and Arne H. Wiedermann

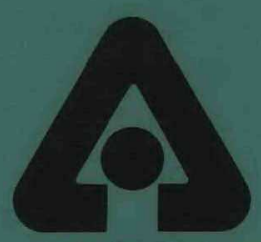

U OfC-AUA-USDOE

ARGONNE NATIONAL LABORATORY, ARGONNE, ILLINOIS Prepared for the U. S. DEPARTMENT OF ENERGY under Contract W-31-109-Eng-38 


\section{DISCLAIMER}

This report was prepared as an account of work sponsored by an agency of the United States Government. Neither the United States Government nor any agency Thereof, nor any of their employees, makes any warranty, express or implied, or assumes any legal liability or responsibility for the accuracy, completeness, or usefulness of any information, apparatus, product, or process disclosed, or represents that its use would not infringe privately owned rights. Reference herein to any specific commercial product, process, or service by trade name, trademark, manufacturer, or otherwise does not necessarily constitute or imply its endorsement, recommendation, or favoring by the United States Government or any agency thereof. The views and opinions of authors expressed herein do not necessarily state or reflect those of the United States Government or any agency thereof. 


\section{DISCLAIMER}

Portions of this document may be illegible in electronic image products. Images are produced from the best available original document. 
The facilities of Argonne National Laboratory are owned by the United States Government. Under the terms of a contract (W-31-109-Eng-38) among the U. S. Department of Energy, Argonne Universities Association and The University of Chicago, the University employs the staff and operates the Laboratory in accordance with policies and programs formulated, approved and reviewed by the Association.

\section{MEMBERS OF ARGONNE UNIVERSITIES ASSOCIATION}

The University of Arizona

Carnegie-Mellon University

Case Western Reserve University

The University of Chicago

University of Cincinnati

Illinois Institute of Technology

University of Illinois

Indiana University

The University of Iowa

Iowa State University
The University of Kansas

Kansas State University

Loyola University of Chicago

Marquette University

The University of Michigan

Michigan State University

University of Minnesota

University of Missouri

Northwestern University

University of Notre Dame
The Ohio State University

Ohio University

The Pennsylvania State University

Purdue University

Saint Louis University

Southern Illinois University

The University of Texas at Austin

Washington University

Wayne State University

The University of Wisconsin-Madison

-NOTICE

This report was prepared as an account of work sponsored by an agency of the United States Government. Neither the United States nor any agency thereof, nor any of their employees, makes any warranty, expressed or implied, or assumes any legal liability or responsibility for any third party's use or the results of such use of any information, apparatus, product or process disclosed in this report, or represents that its use by such third party would not infringe privately owned rights. Mention of commercial products, their manufacturers, or their suppliers in this publication does not imply or connote approval or disapproval of the product by Argonne National Laboratory or the United States Government.

Printed in the United States of America

Available from

National Technical Information Service

U. S. Department of Commerce

5285 Port Royal Road

Springfield, VA 22161

NTIS price codes

Printed copy: $\mathrm{A} 03$

Microfiche copy: A01 
Distribution Categories:

LMFBR--Structural Materials and Design Engineering (UC-79h)

LMFBR - Safety (UC-79p)

\author{
ANL-79-70 \\ ARGONNE NATIONAL LABORATORY \\ 9700 South Cass Avenue \\ Argonne, Illinois 60439
}

\begin{abstract}
NUMERICAL METHOD FOR SOLUTION OF TRANSIENT, HOMOGENEOUS, EQUILIBRIUM, TWO-PHASE FLOWS

IN ONE SPACE DIMENSION
\end{abstract}

by

Yong W. Shin and Arne H. Wiedermann*

Components Technology Division

October 1979

*Affiliated with IIT Research Institute, Chicago, Illinois 

TABLE OF CONTENTS

$\underline{\text { Page }}$

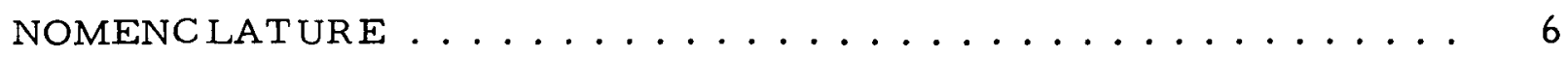

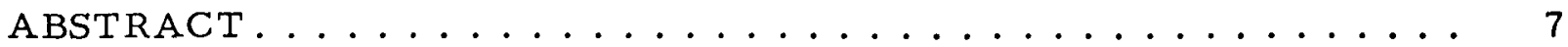

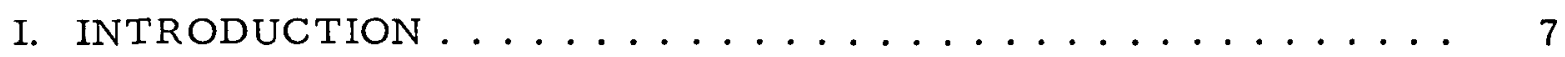

II. GOVERNING DIFFERENTIA L EQUATIONS . . . . . . . . . . 8

III. FINITE-DIFFERENCE PROCEDURE . . . . . . . . . . . . 9

IV. BOUNDARY-NODE SOLUTION METHOD . . . . . . . . . . 10

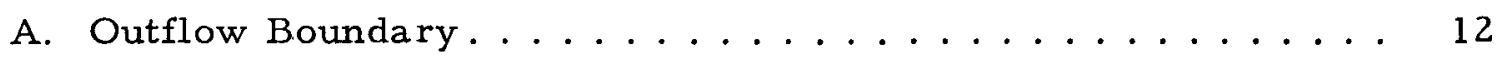

B. Reservoir End. ....................... 13

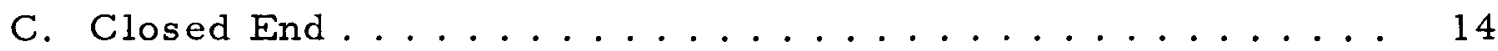

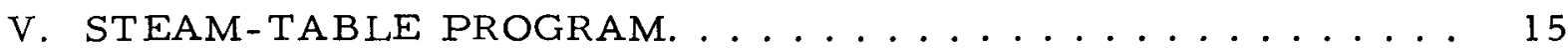

VI. SAMPLE PROBLEM CALCULATIONS. . . . . . . . . . . 15

A. Blowdown from Closed Tube: Fully Open End......... 16

B. Blowdown from Closed Tube: Orificed End. . . . . . . . . 18

C. Reservoir Compression for Water/Steam Mixture . . . . . 18

D. Reservoir Blowdown for Nitrogen Gas ............. 21

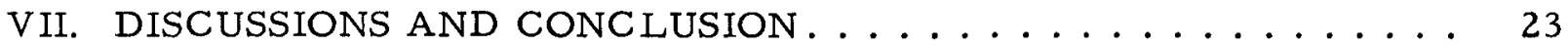

APPENDIX: Derivation of Characteristic Equations. ......... 24

ACKNOWLEDGMENT . . . . . . . . . . . . . . . . . . . 26

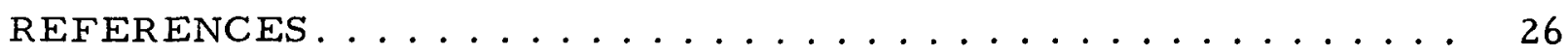




\section{LIST OF FIGURES}

No.

Title

$\underline{\text { Page }}$

1. Grid System for Finite-diffe rence Procedure ........... 9

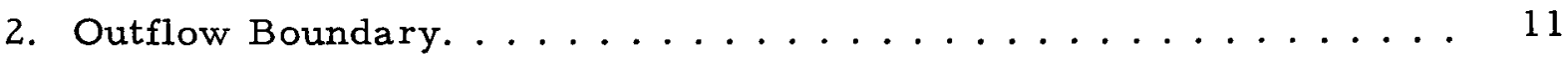

3. Solution Methodology for Outflow Boundary. ........... 12

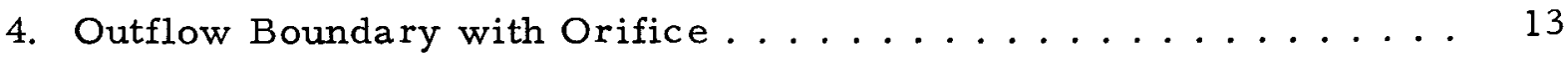

5. Boundary at Reservoir End ................... 14

6. Solution Methodology at Reservoir End .............. 14

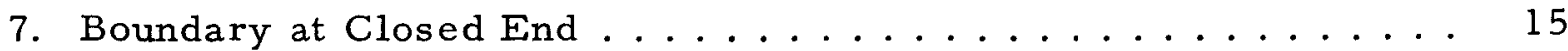

8. Closed-tube Decompression: Fully Open End.......... 16

9. Water/Steam-mixture Decompression Result: Pressure

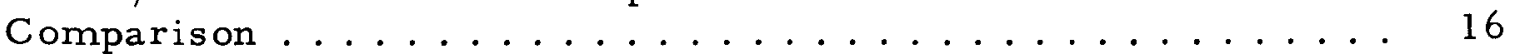

10. Water/Steam-mixture Decompression Result: Blowdown-rate

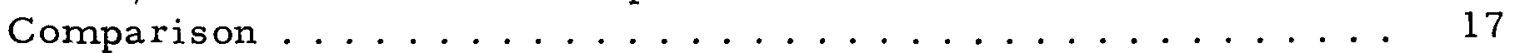

11. Nitrogen Decompression Result: Pressure Comparison . . . . . 17

12. Nitrogen Decompression Result: Blowdown-rate Comparison . . 18

13. Closed-tube Decompression: Orificed End. . . . . . . . . 18

14. Water/Steam-mixture Decompression with Orifice: Pressure

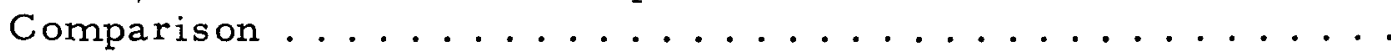

15. Water/Steam-mixture Decompression with Orifice: Blowdown-

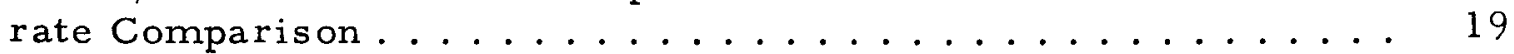

16. Reservoir-evaluation Case .................. 20

17. Hodograph Plane for Reservoir-evaluation Case . . . . . . . . 20

18. Pressure History at Reservoir End for Reservoir-evaluation

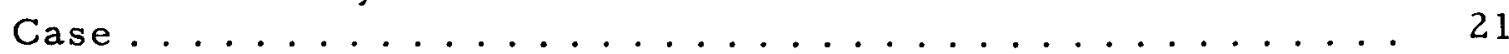

19. Velocity History at Open End for Reservoir-evaluation Case.... 21

20. Reservoir-blowdown Case for Nitrogen . . . . . . . . . . . 22

21. Mass-flow-rate History for Reservoir Blowdown of Nitrogen. . . 22

22. Steady-state Distribution in Tube for Reservoir Blowdown of

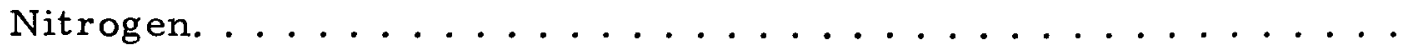


NOMENC LATURE 
NOMENCLATURE

C

$\mathrm{E}$

$\overrightarrow{\mathrm{F}}$

g

i

$\mathrm{p}$

Q

$\mathrm{s}$

$\vec{S}$

t

$\Delta \mathrm{t}$

$\mathrm{T}$

u

$\overrightarrow{\mathrm{U}}$

$\mathrm{x}$

$\Delta \mathrm{x}$

$\beta$

$\rho$

$\theta$

T

Subscripts

$A, B, C, P$

1,2

$\mathrm{T}, \mathrm{R}$

$\mathrm{P}^{\prime}$

0
Sonic speed

Total energy, $i+u^{2} / 2$

Flux vector in the conservation equation defined by Eq. 6

Gravity

Internal energy

Pressure

Heat addition to fluid per unit volume of fluid

Entropy

Source vector in the conservation equation defined by Eq. 6

Time

Time step used in the numerical procedure

Temperature

Velocity of fluid

Vector representing transport quantities defined by Eq. 6

Space coordinate along the tube

Nodal length used in the numerical procedure

$\Delta \mathrm{t} / \Delta \mathrm{x}$

Fluid density

Inclination angle representing tube orientation

Tube wall friction

Refers to nodal points used in the numerical procedure

Refers to tentative points in $t-x$ plane used in the numerical procedure

Refers to intercept points on current time plane of the characteristics

Refers to mapped state of the solution state at point $P$

Refers to stagnation state 


\title{
NUMERICAL METHOD FOR SOLUTION OF TRANSIENT, HOMOGENEOUS, EQUILIBRIUM, TWO-PHASE FLOWS \\ IN ONE SPACE DIMENSION
}

by

Yong W. Shin and Arne H. Wiedermann

\begin{abstract}
This report presents a solution method for transient, homogeneous, equilibrium, two-phase flows of a singlecomponent fluid in one space dimension. The method combines a direct finite-difference procedure and the method of cha racteristics. The finite-difference procedure solves the interior points of the computing domain; the boundary information is provided by a separate procedure based on the characteristics theory. The solution procedure for boundary points requires information in addition to the physical boundary conditions. This additional information is obtained by a new procedure involving integration of characteristics in the hodograph plane.

Sample problems involving various combinations of basic boundary types are calculated for two-phase water/steam mixtures and single-phase nitrogen gas, and compared with independent method-of-characteristics solutions using very fine characteristic mesh. In all cases, excellent agreement is demonstrated.
\end{abstract}

\section{INTRODUCTION}

Design considerations for an LMFBR intermediate heat-transport system must include the potential for water/steam leakage from the highpressure tubeside into the shellside sodium of the steam generator. Because the ensuing chemical reaction can produce large pressure and thermal loadings that propagate through the system, the amount and rate of leakage are important factors that determine the extent of these loadings. Hence, accurate means of determining these parameters are essential tools for designers to ensure that the system is structurally sound and can withstand the potential loadings, and/or to design an adequate relief system.

This report discusses a method that enables accurate computation of the complete tubeside transient from which time-dependent leak rates can be obtained. The method uses a direct finite-difference technique for computation of interior nodes. For boundary nodes, a special procedure is developed which 
uses the characteristic equations. Basically, the procedure involves searching of intersections of the characteristics and the boundary conditions in the hodograph plane. Actually, integration of characteristics is necessary because the characteristics are severely curved due to the drastic change in acoustic impedance of the fluid. This is especially true when the characteristic crosses the liquid-saturation line where the sonic speed is essentially discontinuous.

Earlier attempts at similar tasks used certain approximations in the boundary treatments. For example, as was usually done by many others, averaging of impedances at both ends of characteristics was used by Galluzzo, ${ }^{1}$ and Berry and Daley. ${ }^{2}$ This approximation was adequate for some flow regimes and yielded reasonable results, but inadequate for flow regimes where the states are largely different between adjacent nodes. In such instances, the approximation introduced large errors at the boundary and caused a complete breakdown of the procedure. This was noted in particular at the break end, where the large gradient in the state exists.

Lyczkowski, Grimesey, and Solbrig ${ }^{3}$ introduced another type of approximation in their boundary-end treatment which was partially successful in predicting the Edwards problem. ${ }^{4}$ Although the interior transient result agreed reas onably well with the experimental data, a close examination of their work revealed that the pressure and temperature transients at interior points were not very sensitive to the boundary treatment. The blowdown rate is a sensitive parameter, and a comparison of the blowdown rates showed a significant discrepancy between the result of the present method and the approximate approach.

The method presented here is a new methodology that provides exact boundary treatment since the solution state at the boundary node is determined by a distinct point in the hodograph plane. No assumptions or approximations are needed because the available characteristics exactly supplement the information lacking at the boundaries.

\section{GOVERNING DIFFERENTIAL EQUATIONS}

The governing equations are the conservation equations of mass, momentum, and energy of one-dimensional compressible flows. The equations considered are for homogeneous, equilibrium, two-phase flows of a singlecomponent fluid. The equations are written in a conservation form as

$$
\begin{aligned}
& \frac{\partial}{\partial t} \rho+\frac{\partial}{\partial x} \rho u=0, \\
& \frac{\partial}{\partial t} \rho u+\frac{\partial}{\partial x}\left(\rho u^{2}+p\right)=\rho g \cos \theta-\tau,
\end{aligned}
$$


and

$$
\frac{\partial}{\partial t} \rho E+\frac{\partial}{\partial \mathbf{x}}[u(\rho E+p)]=\rho g \cos \theta \cdot u+Q
$$

where $\theta$ is the inclination angle between the gravity force and the positive $x$ axis, $\tau$ is the friction acting on the wall per unit length and unit crosssectional area, $Q$ is the heat addition to the fluid per unit volume, and $E$ is the total energy defined by

$$
E=i+\frac{1}{2} u^{2}
$$

These equations contain four dependent variables: $\rho, p, i$, and $u$. An additional equation required for solution is the equation of state written in a functional form,

$$
p=p(\rho, i)
$$

The three governing equations are in the form of the generalized trans port equation,

$$
\frac{\partial}{\partial t} \vec{U}+\frac{\partial}{\partial \mathbf{x}} \vec{F}=\vec{S}(\vec{U})
$$

where $\vec{U}, \vec{F}$, and $\vec{S}$ are vectors with three elements each representing the trans port quantity, flux, and source, respectively.

\section{FINITE-DIFFERENCE PRODEDURE}

The procedure used for interior node solution is the explicit technique based on the two-step Lax-Wendroff scheme. ${ }^{5}$ It is briefly illustrated here for a uniform nodal spacing, $\Delta x=$ constant. Figure 1 depicts a typical grid system, rectangular in the $x-t$ coordinate plane. Points $A, B$, and $C$ are at the current time $t_{0}$ where the solution (the values of dependent variables) is known, and point $P$ is the interior point for which the solution is sought; $P$ is at an advanced time $t_{0}+\Delta t$.

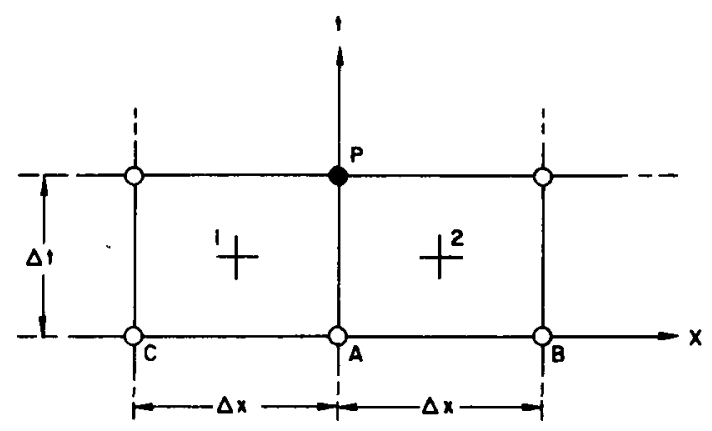

Fig. 1

Grid System for Finitedifference Procedure 
In the first step, intermediate, half-step values are calculated for points 1 and 2 of Fig. 1 as

$$
\vec{U}_{1}=\frac{1}{2}\left(\vec{U}_{A}+\vec{U}_{C}\right)+\frac{1}{2} \beta\left(\vec{F}_{C}-\vec{F}_{A}\right)+\frac{1}{4} \beta \Delta x\left(\vec{S}_{A}+\vec{S}_{C}\right)
$$

and

$$
\overrightarrow{\mathrm{U}}_{2}=\frac{1}{2}\left(\overrightarrow{\mathrm{U}}_{\mathrm{A}}+\overrightarrow{\mathrm{U}}_{\mathrm{B}}\right)+\frac{1}{2} \beta\left(\overrightarrow{\mathrm{F}}_{\mathrm{A}}-\overrightarrow{\mathrm{F}}_{\mathrm{B}}\right)+\frac{1}{4} \beta \Delta \mathrm{x}\left(\overrightarrow{\mathrm{S}}_{\mathrm{A}}+\overrightarrow{\mathrm{S}}_{\mathrm{B}}\right)
$$

where $\beta=\Delta t / \Delta x$. These intermediate values $\vec{U}_{1}$ and $\vec{U}_{2}$ are used to calculate flux vectors $\vec{F}_{1}$ and $\vec{F}_{2}$. The equation of state of the form given by Eq. 5 is also used.

The second step yields the final solution at $\mathrm{P}$ :

$$
\vec{U}_{P}=\vec{U}_{A}+\beta\left(\vec{F}_{1}-\vec{F}_{2}\right)+\frac{1}{2} \beta \Delta x\left(S_{1}+S_{2}\right)
$$

This procedure is repeated for all interior nodes before time can be advanced. For boundary nodes (two end nodes of a tube), all values of the dependent variables must be given. Obtaining solutions at all interior and boundary nodes constitutes one-step computation by which the solution is advanced by one time step $\Delta t$. In general, the order of computation (i.e., either interior nodes first, followed by boundary nodes, or vice versa) is immaterial. In certain types of boundary conditions (e.g., nonreflecting condition), the boundary specification requires interior information at the advanced time. In this case, the interior-node computation must be performed first. It is therefore safe to do the boundary-node computation after completion of interior nodes.

The procedure is presented here for uniform nodal spacing. It is equally applicable to variable node spacings ( $\Delta \mathbf{x} \neq$ constant). The advantage in the variable spacing is the saving in computation time by reducing the number of computational points in unimportant parts of the domain. The disadvantage is that it introduces errors resulting from numerical smearing due to the small Courant number in regions of large $\Delta \mathbf{x}$. This is because the overall procedure is limited in its time step by the CFL (Courant-Frederick-Lewy) condition,

$$
\Delta t \leq \Delta x /(c+|u|)_{\max }
$$

\section{BOUNDARY-NODE SOLUTION METHOD}

Following the usual practice, a quasi-steady state is assumed to exist at the boundary: At each step of computation the flow condition at the boundary 
node adjusts immediately to the exterior condition, and a steady-state relationship exists between the boundary and the outside. This is justified as long as the tube diameter is small compared to the overall dimension of the system, i.e., the tube length. This condition is considered satisfied in most applications.

The additional information required for complete specification of conditions at the boundary is obtained from characteristic equations. These equations are derived in the appendix. The $\mathrm{T}$-characteristic (particle-path line $\Delta x=u \Delta t$ ) is used first to obtain the entropy at the unknown point: the boundary node at advanced time $t_{0}+\Delta t$. The $T$-characteristic is

$$
\frac{\mathrm{ds}}{\mathrm{dt}}=\frac{1}{\rho \mathrm{T}}\left(\mathrm{u}_{\mathrm{T}}+\mathrm{Q}\right)
$$

As derived in the appendix, the $R$ characteristic $[\Delta x=(c+u) \Delta t]$ and $S$ characteristic $[\Delta x=(c-u) \Delta t]$ are, respectively,

$$
\frac{d p}{d t}+\rho c \frac{d u}{d t}=\frac{1}{\rho}\left(\frac{\partial p}{\partial i}\right)_{\rho}(u \tau+Q)+c(\rho g \cos \theta-\tau)
$$

and

$$
\frac{d p}{d t}-\rho c \frac{d u}{d t}=\frac{1}{\rho}\left(\frac{\partial p}{\partial i}\right)_{\rho}(u \tau+Q)-c(\rho g \cos \theta-\tau) .
$$

In all boundary treatments, the solution state is sought at an average entropy $\bar{s}$. In the outflow case, for example (see Fig. 2b),

$$
\bar{s}=\frac{1}{3}\left(s_{P}+s_{R}+s_{T}\right)
$$

Entropies between nodes such as $R$ and $T$ are obtained by linear interpolation,

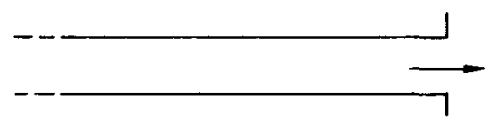

(a) PHYSICAL CONFIGURATION

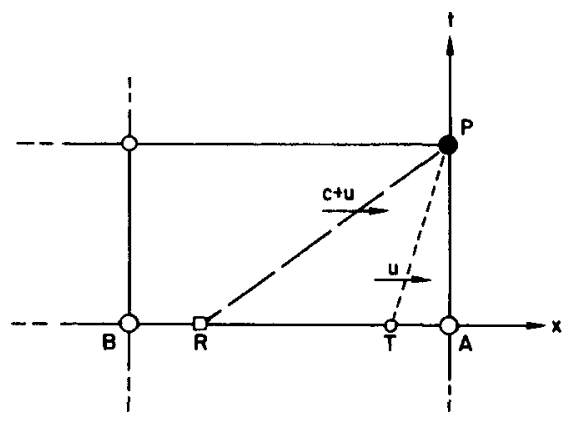

Fig. 2

Outflow Boundary

(b) WAVE DIAGRAM 
using states at nodes $A$ and $B$. Likewise, all terms on the right-hand side of Eqs. 10-12 are evaluated by interpolation. Since entropy is used as an independent property, two additional forms of steam tables are required:

$$
\begin{aligned}
& i=i(p, s) ; \\
& \rho=\rho(p, s) .
\end{aligned}
$$

In applying the characteristics, we use a finite-step integration procedure in the hodograph plane. The result is that the characteristics are often curved in the solution plane. The curvature is most pronounced when the state change is large, as in the case of a flashing transient.

\section{A. Outflow Boundary}

The physical configuration of an outflow boundary is shown in Fig. 2a. Flow direction $u$ is positive; hence, both $T$ and $R$ characteristics are present as shown in Fig. $2 \mathrm{~b}$. T characteristic determines $\bar{s}$. The solution methodology is described in Fig. 3. The solution state is simply the intersection of the

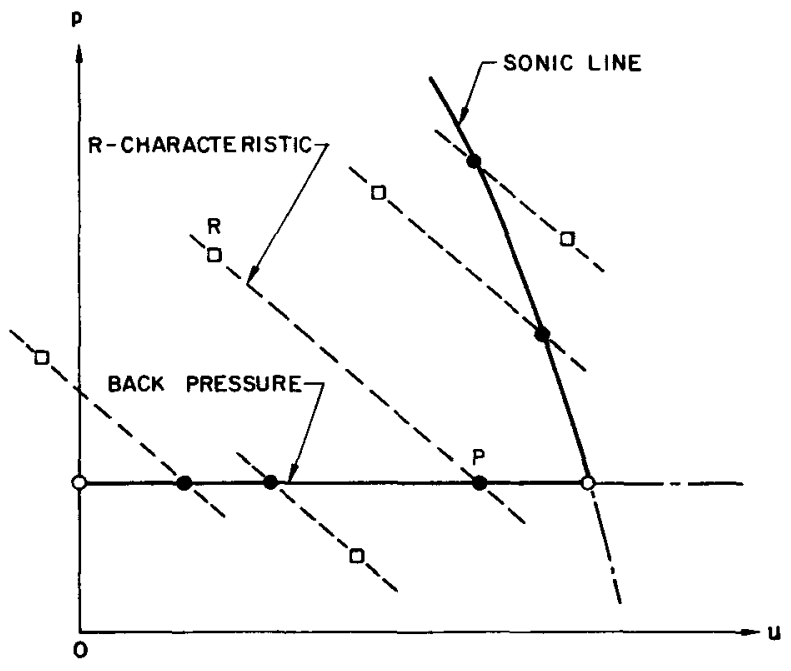

Fig. 3. Solution Methodology for Outflow Boundary $R$ characteristic and the boundary condition in the hodograph plane $(s=\bar{s})$. The boundary condition is either the back pressure (outside pressure) or the sonic line. If $R$ lies in the supersonic branch, a supersonic outflow is possible. In this case, a check is made on the interior state (state B of Fig. 2b) to determine this possibility. If $B$ is in supersonic state, the supersonic outflow is admitted as a solution state. Otherwise, $P$ lies on the sonic line.

When the outflow end is not fully open, as in a partial tube rupture (outflow with an orifice as shown in Fig. 4a), the sonic state at the orifice corresponds to a subsonic state in the interior. In the supersonic branch,

however, the corresponding state in the interior is supersonic. Hence, the sonic line maps to two lines, and these are now the boundary conditions for the orificed case. The region between the two mappings of the sonic line represents nonadmissible solution states. $P$ cannot assume a state lying in this region.

Mapping of the back pressure is also indicated in Fig. 4b. The solution state is the intersection of the $R$ characteristic with the mapping of the sonic line or the back pressure line, as illustrated in Fig. 4b. Except for the mapping, the procedure is identical to the fully open case discussed previously. Mapping of states is based on the constancy requirements of mass and total enthalpy, 


$$
P_{P^{A}} A_{P^{u}}^{u_{P}}=\rho_{P^{\prime}} A_{P^{\prime}} u_{P^{\prime}}
$$

and

$$
i_{P}+\frac{p_{P}}{\rho_{P}}+\frac{1}{2} u_{P}^{2}={ }^{i} P^{\prime}+\frac{p_{P}}{\rho_{P^{\prime}}}+\frac{1}{2} u_{P^{\prime}}^{2} .
$$

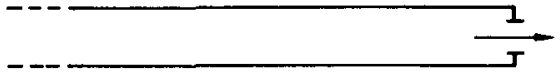

(a) PHYSICAL CONFIgURATION

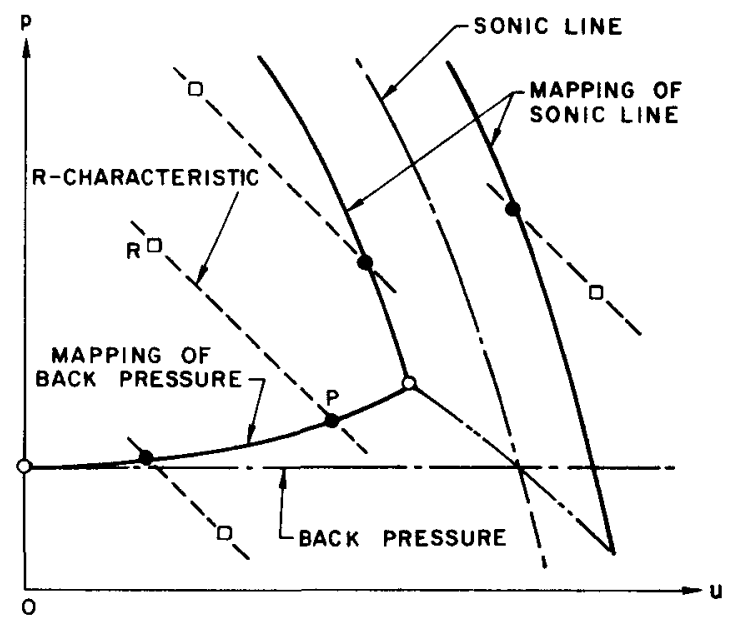

Fig. 4

Outflow Boundary with Orifice

(b) SOLUTION METHODOLOGY

B. Reservoir End

The boundary condition at the reservoir end is the energy line (line of constant total enthalpy) defined by

$$
h_{0}=i_{P}+\frac{p_{P}}{\rho_{P}}+\frac{1}{2} u_{P}^{2},
$$

where $P$ is the solution state in the hodograph plane. Figure 5a shows the physical configuration where the flow accelerates from the high-pressure reservoir into the tube. The wave diagram shown in Fig. 5b indicates that the $S$ characteristic applies. The solution state $P$ is the intersection of the $S$ characteristic and the energy line (see Fig. 6). If $P$ is found in the negativevelocity region, it implies that a flow reversal exists.

State $P$ may lie in the supersonic branch, as illustrated in Fig. 6. The solution state in this case is state $C$ (intersection of energy line and sonic line) instead of the usual intersection of the $S$ characteristic with the energy line. This treatment implies that the supersonic acceleration is not admitted as a solution state at the reservoir end. The possibility of a smooth-contoured 
entrance region enabling such acceleration is excluded here, since geometric details are ignored. In most applications, the entrance region is geometrically abrupt (as in most designs of heat-exchanger plenum entrance to heat-transfer tubes) for which the limiting treatment as described above is considered suitable.

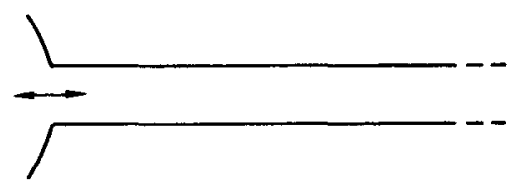

(a) PMYSICAL CONFIGURATION

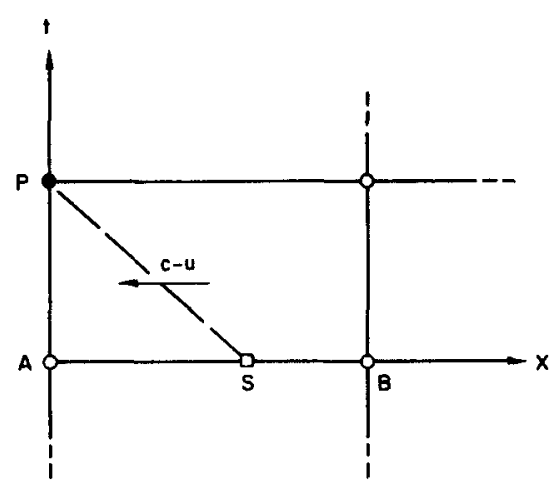

(b) WAVE DIAGRAM

Fig. 5. Boundary at Reservoir End

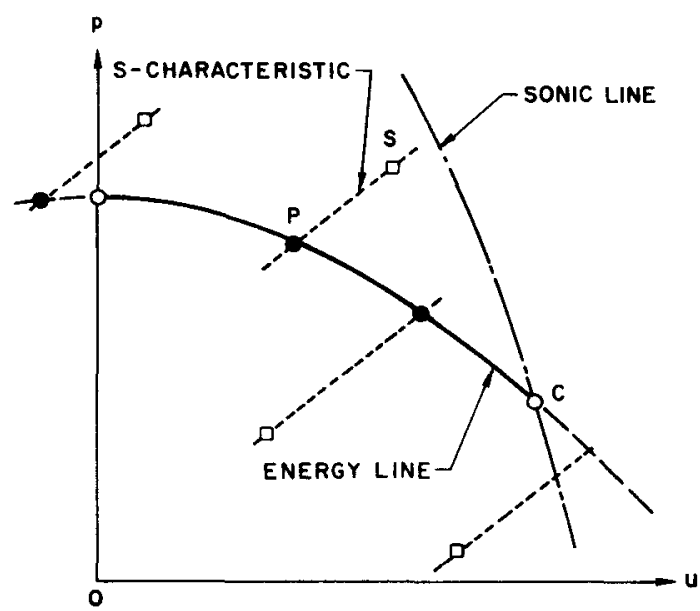

Fig. 6. Solution Methodology at Reservoir End

\section{Closed End}

The boundary condition for a closed end is $u=0$. Values of other dependent variables remain to be solved for. A similar procedure may be followed, and the intersection of characteristics and boundary conditions may be sought in the state plane at some representative entropy $\bar{s}$. Entropy $\bar{s}$ may be chosen by an average of entropies at terminal points of characteristics. Pertinent characteristics here are the $S$ and $T$ characteristics. The boundary condition is the vertical line $u=0$ in the hodograph plane. Hence, the solution state $P$ lies on the $P$ axis at the point where the $S$ characteristic intersects. Conceptually, this procedure is identical to the preceding boundary treatments and hence is not elaborated further.

An alternative procedure is described here which is simpler and whose accuracy is consistent with the finite-difference scheme used for interior nodes. This procedure uses the symmetry property of flow at the closed end: The flow on the left of the closed end of Fig. 7 is the mirror image of that on the right. To represent this in the finite-difference procedure, a fictitious point $l$ is assumed for which flow properties are assigned that are identical to point 2, except that the flow direction is reversed. Thus only Eq. 8 is necessary. This method is used throughout the sample problem calculations in this report. 
(a) PHYSICAL CONFIGURATION

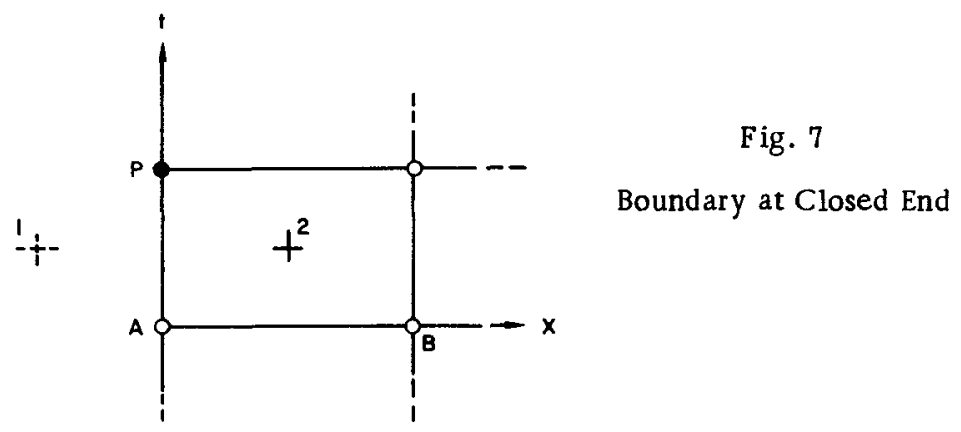

(b) SOLUTION METHODOLOGY

V. STEAM-TABLE PROGRAM

In addition to Eqs. 5, 14, and 15, the following functional forms are required:

$$
c=c(p, s)
$$

and

$$
\left(\frac{\partial p}{\partial i}\right)_{p}=\left(\frac{\partial p}{\partial i}\right)_{p}(p, s)
$$

An existing steam-table program with flexibility in the choice of independent variables has been modified to include wider choices. The sonic speed $c$ is computed on the basis of thermodynamic equilibrium between phases.

The equation of state used in the program is based on Keenan's for mulation, ${ }^{7}$ which is valid to 1000 bars $(100 \mathrm{MPa})$ and $1300^{\circ} \mathrm{C}$. This formulation expresses the Helmholtz function in terms of temperature and specific volume for both liquid and vapor phases. For other pairs of independent variables, an iteration procedure is used, starting from given approximate values. Accuracy depends on the tolerance limits assigned to the iteration procedure. The steam-table program has been performed satisfactorily in all applications to date.

\section{SAMPLE PROBLEM CALCULATIONS}

Several sample problems involving various combinations of boundary types were calculated and the results compared with reference solutions. These problems include two-phase water/steam mixture and single-phase nitrogen gas. The reference solutions are method-of-characteristics solutions that are considered nearly exact as they are obtained with a very fine mesh of characteristics. 
A. Blowdown from Closed Tube: Fully Open End

The tube under consideration is $5.1 \mathrm{~m}$ long and is initially at a uniform state. At $t=0$, one end of the tube is suddenly opened and the subsequent blowdown is examined. The pressure in the tube is higher than the ambient (atmospheric), and an outflow is maintained at the open end.

As shown in the wave diagram (Fig. $8 \mathrm{~b}$ ), a centered rarefaction system develops at the open end and propagates into the tube. These waves remain

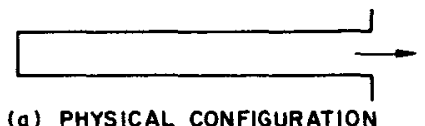

(d) PHYSICAL CONFIGURATION

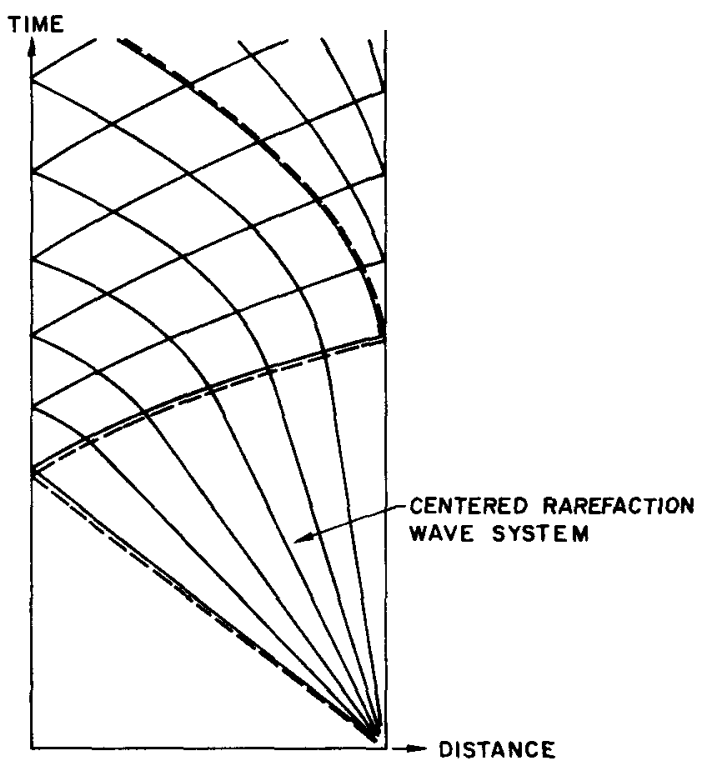

(b) WAVE DIAGRAM

Fig. 8. Closed-tube Decompression: Fully Open End expansion waves as they reverberate between the two ends. The flow is subsonic in the entire region and duration. At the open end, a sonic state is maintained until the pressure approaches the back pressure. The dashed line in Fig. 8b represents the initial expansion characteristic and its reflections.

The results of the water/steammixture decompression together with the refer ence solutions a re shown in Figs. 9 and 10. A uniform initial state of $13.79 \mathrm{MPa}$, $335.4^{\circ} \mathrm{C}$ and $51 \%$ quality is considered. Since the refe rence solution is for no friction, the friction in the finite-difference solution is suppressed by considering an arbitrarily large-diameter tube. There is excellent agreement in this comparison. The cusps in the method-of-characteristics solutions are seen somewhat rounded off in the finitedifference solutions. Small overshoots appearing for the open end during early time in the finite-difference solutions are due to numerical features typically observed during starting transients. As the deviation from reference solution is small, no special effort has been made to improve this point.

Fig. 9

Water/Steam-mixture Decompression Result: Pressure Comparison

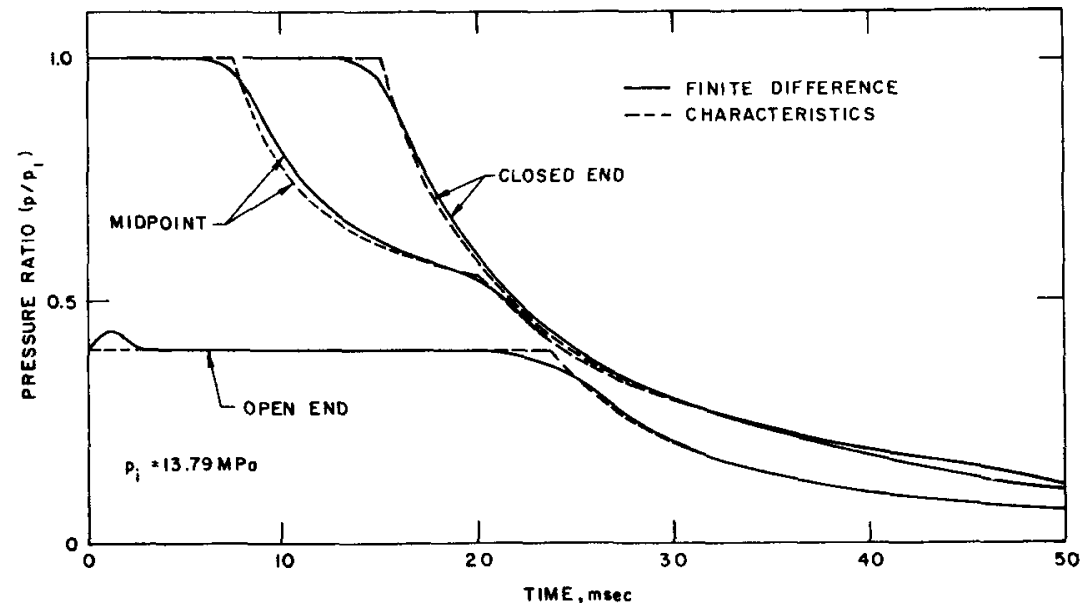




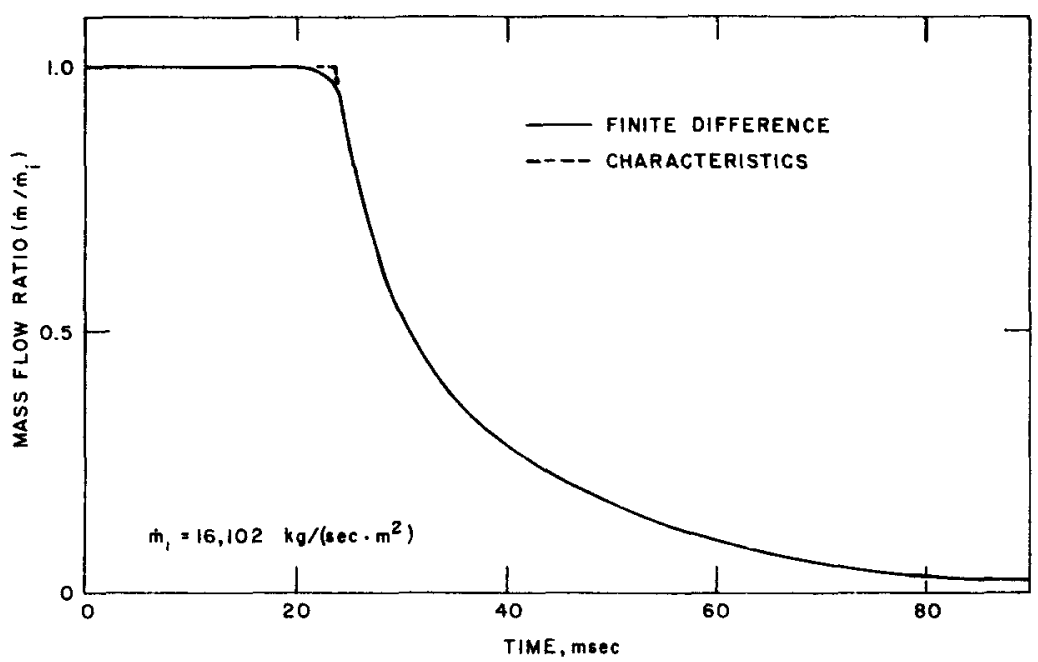

Fig. 10. Water/Steam-mixture Decompression

Result: Blowdown-rate Comparison

Blowdown of nitrogen gas at $1.379 \mathrm{MPa}$ and $37.8^{\circ} \mathrm{C}$ from the same tube was calculated, and the results are compared with reference solutions in Figs. 11 and 12. In all respects, the results resemble those of the water/ steam-mixture case. The agreement between the two solution methods is similarly excellent.

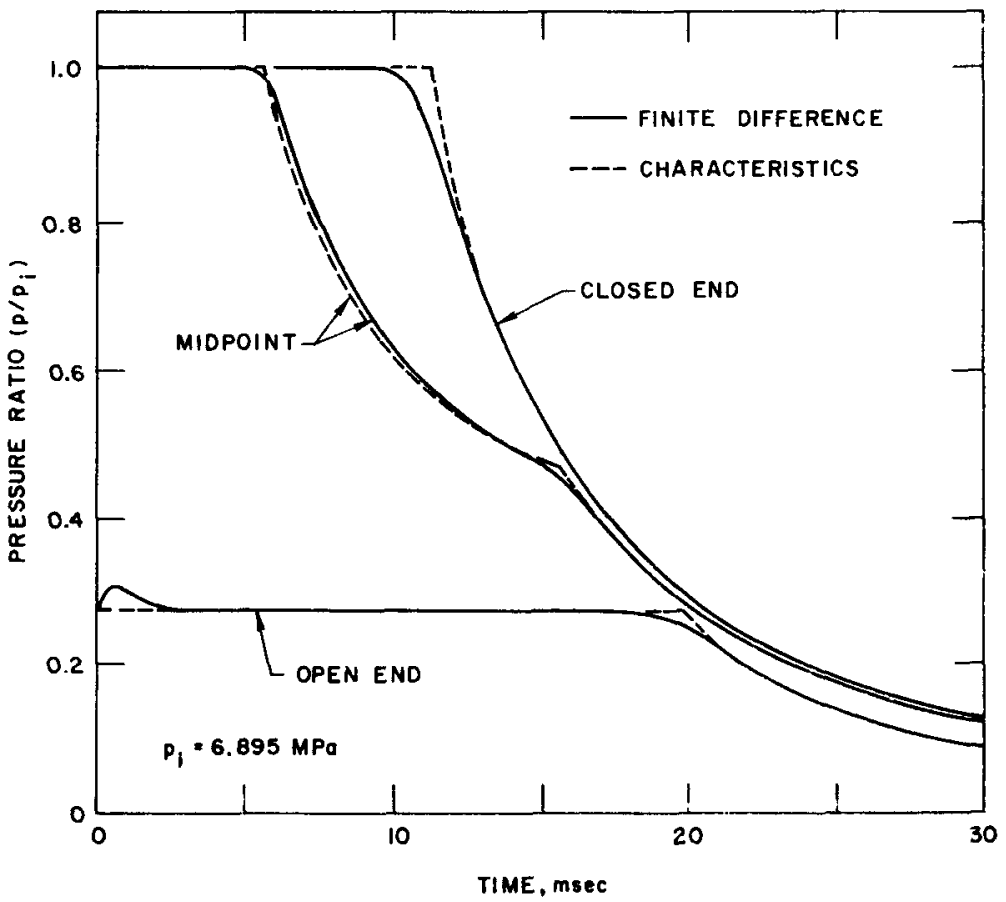

Fig. 11. Nitrogen Decompression Result: Pressure Comparison 


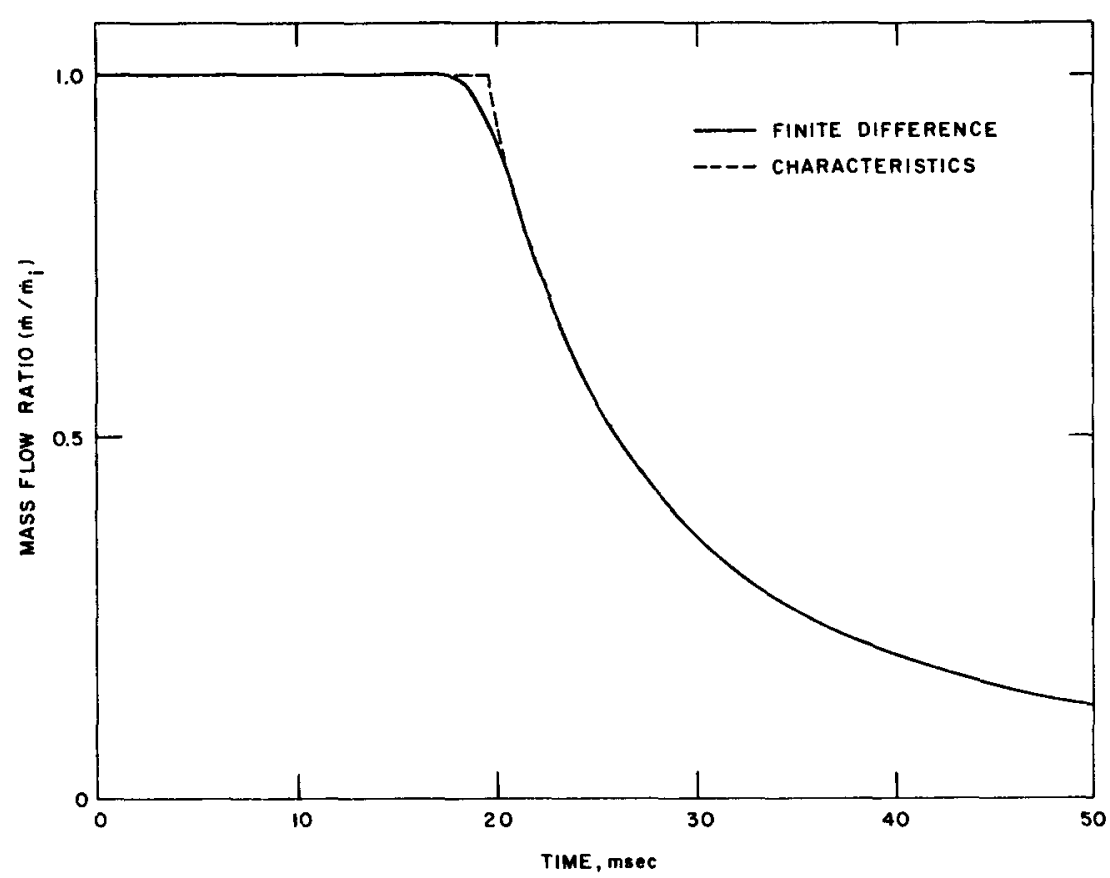

Fig. 12. Nitrogen Decompression Result: Blowdown-rate Comparison

B. Blowdown from Closed Tube: Orificed End

Effects of an orifice at the open end was studied for the foregoing water/steam-mixture decompression. Figure 13 describes the physical con-

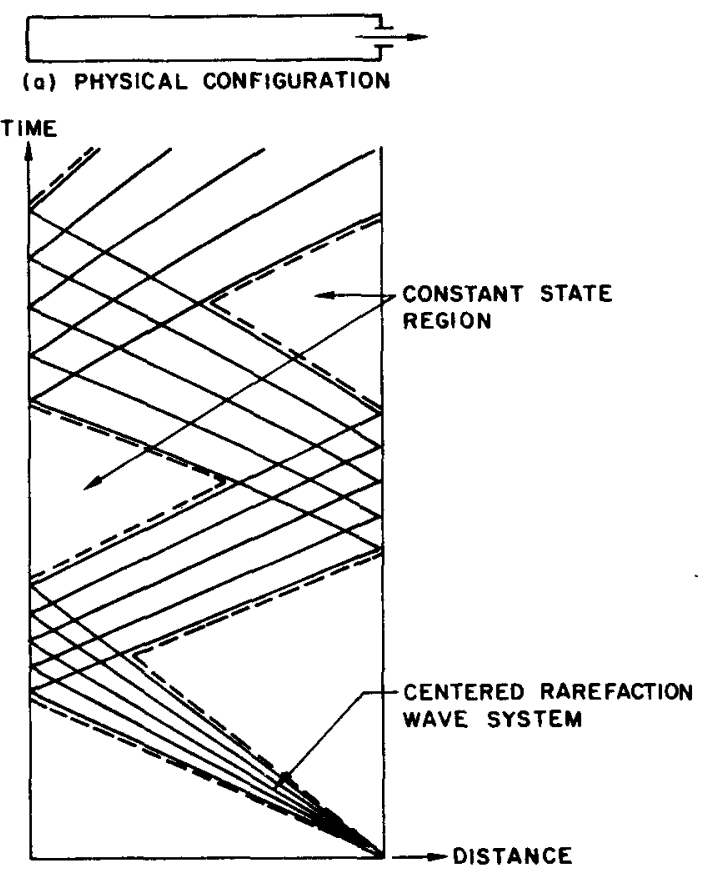

(b) WAVE DIAGRAM

Fig. 13. Closed-tube Decompression: Orificed End figuration and the wave diagram. The area reduction due to the orifice is $50 \%$. The presence of the orifice creates regions of constant states at both the open end and the closed end, with the size of the region diminishing with time. The history plots at the open end (likewise at the closed end) exhibit intermittent finite plateaus (see Figs. 14 and 15), the lengths of which decrease with time. The outflow state is subsonic at all times.

\section{Reservoir Compression for Water/ Steam Mixture}

As described in Fig. 16, a compression wave is sent into the tube from the reservoir end which reflect's at the open end as a centered rarefaction-wave system. The strength of the shock wave considered here is not high enough to result in a sonic or supersonic outflow state. The results at the ends will therefore indicate step changes in the history plots. The reservoir condition is $13.79 \mathrm{MPa}, 335.4^{\circ} \mathrm{C}$, and $51 \%$ quality. The tube is at a uniform state of $12.41 \mathrm{MPa}, 327.2^{\circ} \mathrm{C}$, and 
$50 \%$ quality. The initial entropies of the reservoir and the tube are approximately the same. The back pressure is set equal to the initial tube pressure, 12. $41 \mathrm{MPa}$.

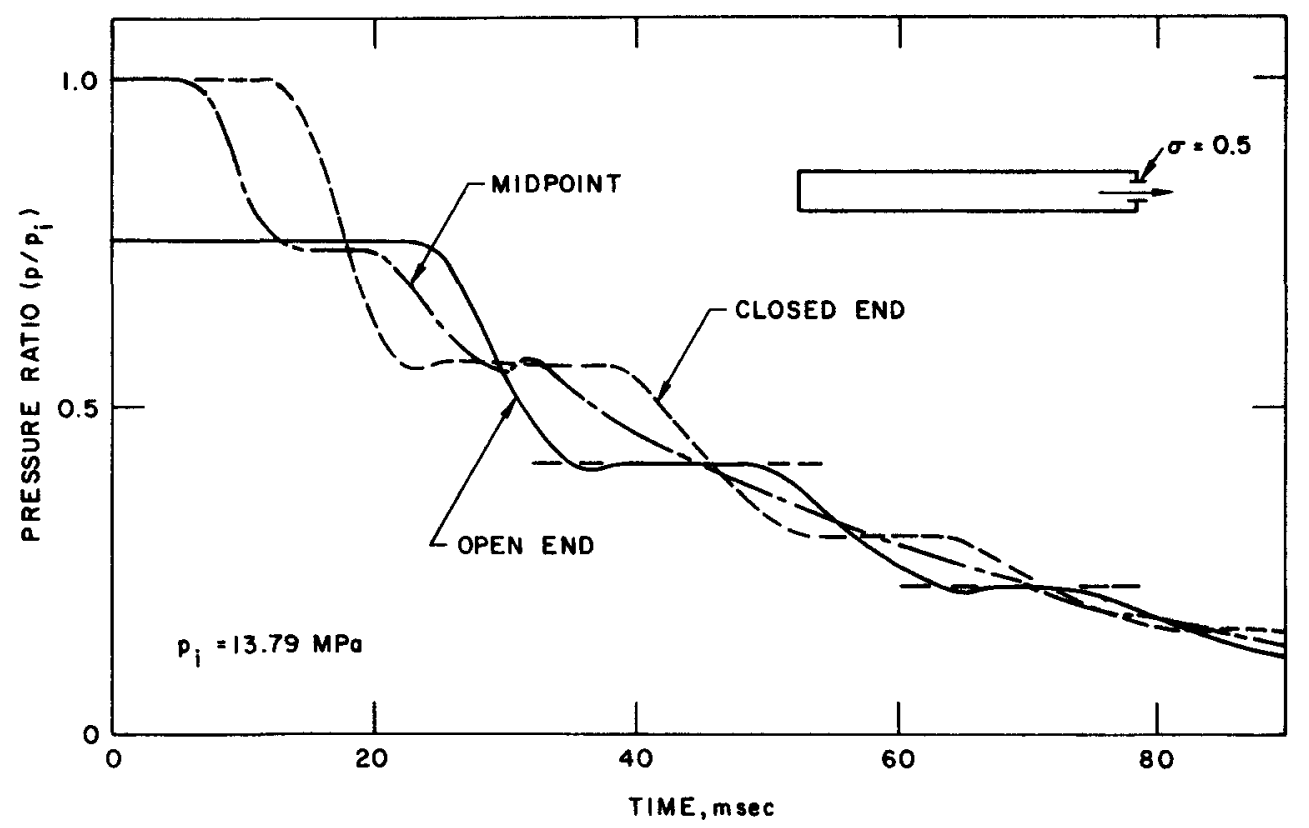

Fig. 14. Water/Steam-mixture Decompression with Orifice: Pressure Comparison

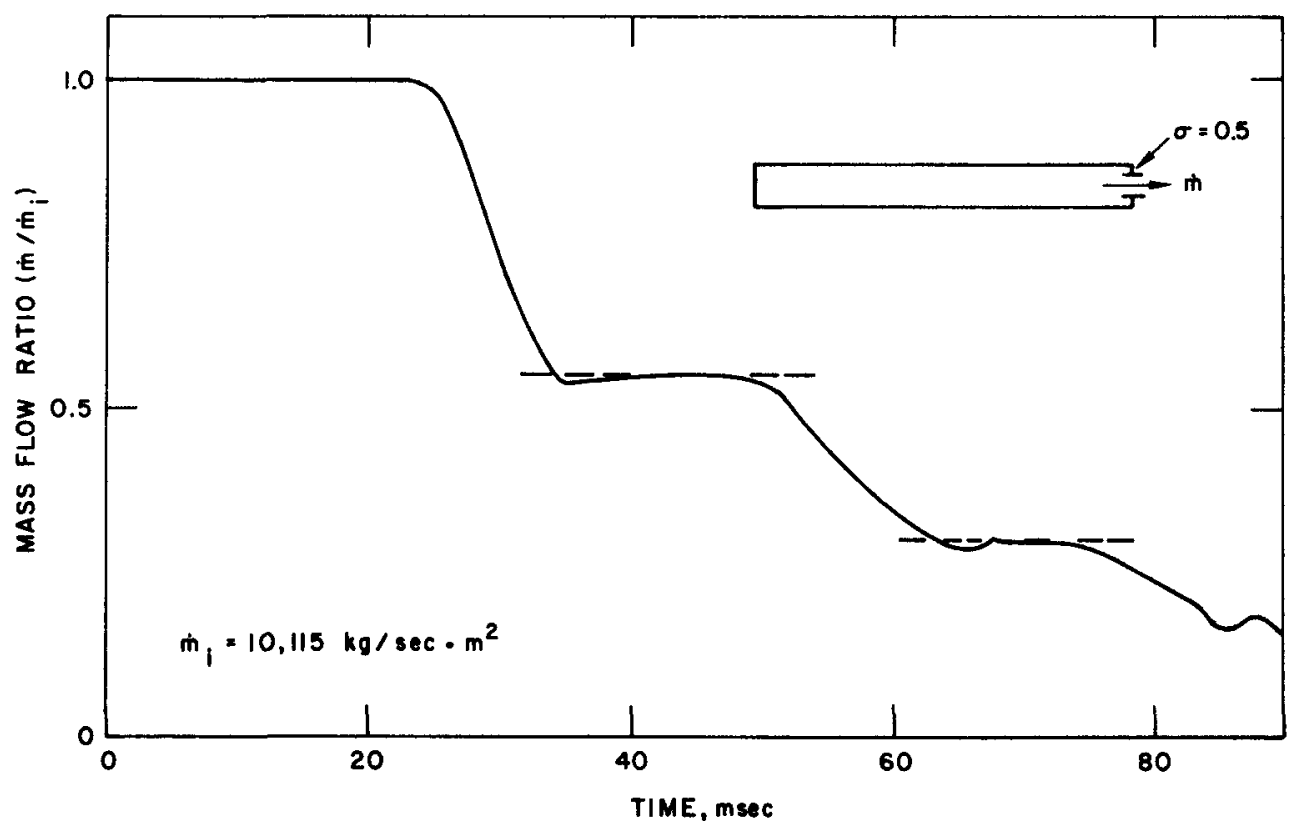

Fig. 15. Water/Steam-mixture Decompression with Orifice: Blowdown-rate Comparison 


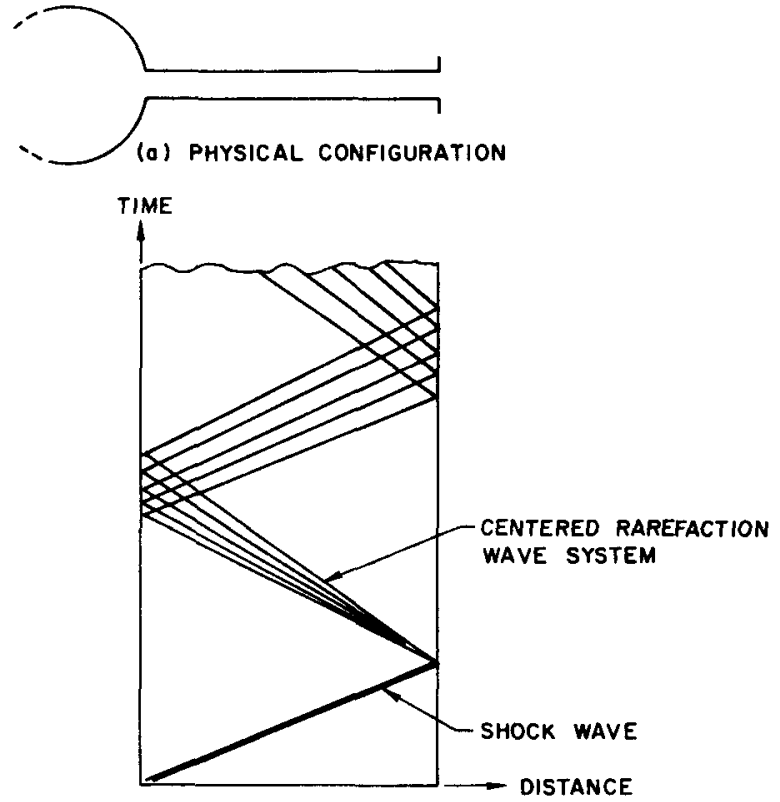

(b) WAVE DIAGRAM

The hodograph plane is shown in Fig. 17. The solution states at the reservoir end lie on the energy line moving downward from the reservoir state. Intersections of the reverberating characteristics with the energy line are the solution states at the reservoir end; $S_{1}$ is the first solution state. In the absence of friction, $S_{N}$ is the limiting solution state corresponding to the steady-state solution. When a steady-state solution is reached, the entire tube will be at $\mathrm{S}_{\mathrm{N}}$. The states at the open end are the intersections of the reverberating characteristics with the constant-pressure line ( $\mathrm{p}=$ 12. $41 \mathrm{MPa}$ ). When friction is included, the limiting state $S_{N}$ is not attained. Rather, there exists a gradient with the limiting state at the reservoir $S_{N^{\prime}}$,

Fig. 16. Reservoir-evaluation Case and that at the open end $S_{N}$. The intermediate points between the ends would be the states along the dotted line connecting the limiting states. The pressure history at the reservoir is shown in Fig. 18, where both cases with and without friction are presented. Similarly, the velocity history is shown in Fig. 19. Again, the friction tends to retard the flow. The step changes in the history plots are clearly indicated.

Fig. 17

Hodograph Plane for Reservoir-evaluation Case

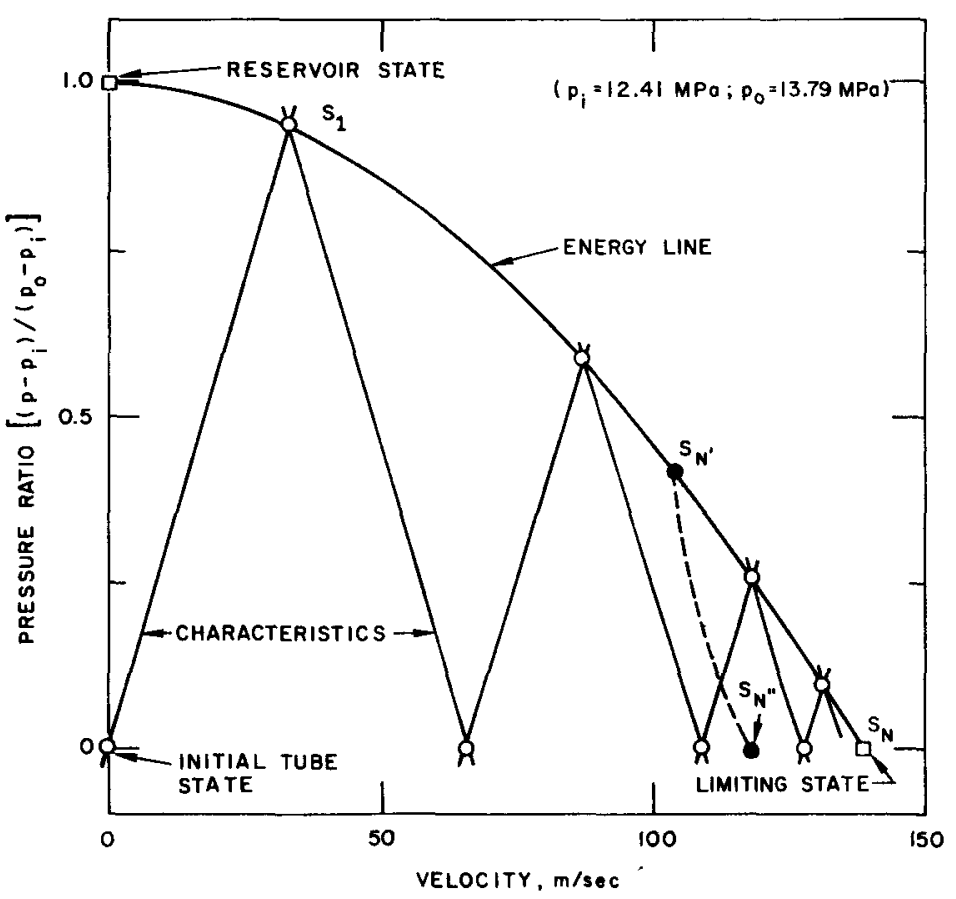




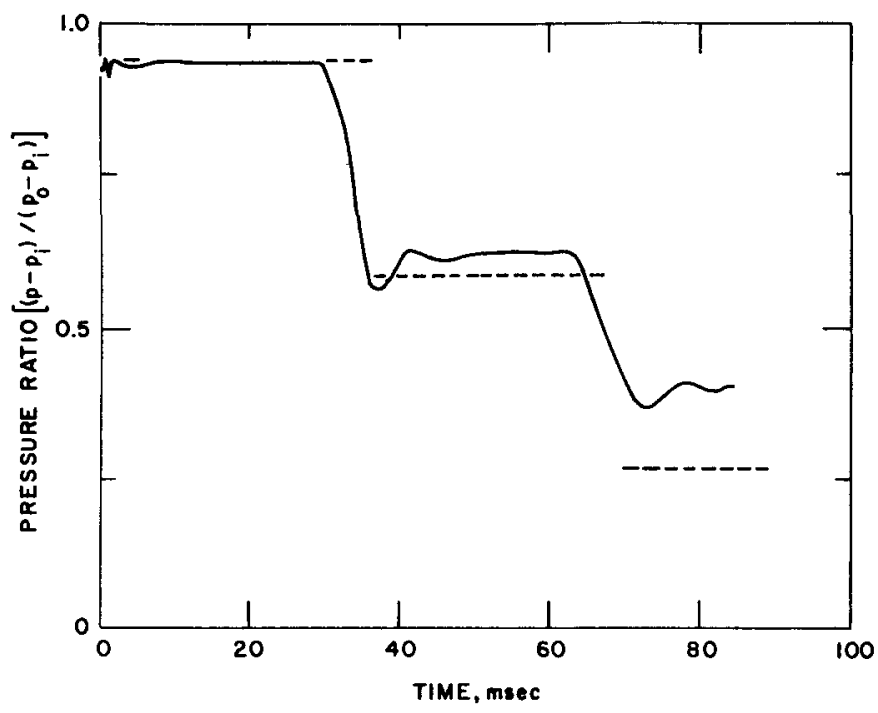

Fig. 18

Pressure History at Reservoir End for Reservoir-evaluation Case

Fig. 19

Velocity History at Open End for Reservoir-evaluation Case

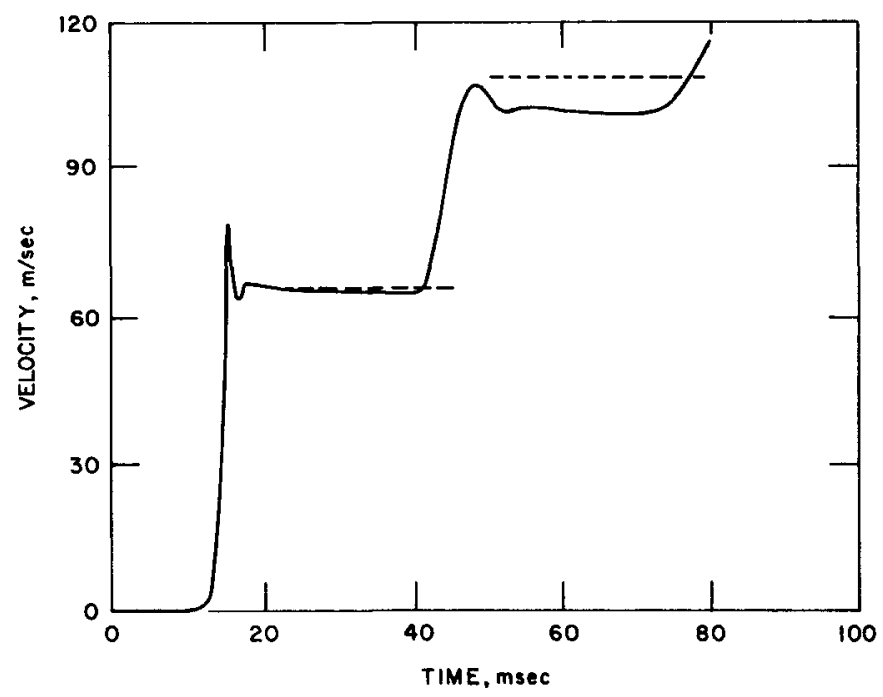

D. Reservoir Blowdown for Nitrogen Gas

Unlike the closed-tube blowdown case, the outflow state in the reservoir blowdown can be in the supersonic state. In fact, a certain finite region near the open end is in the supersonic state. This is indicated in the wave diagram shown in Fig. 20. The case considered here is a uniform state (both reservoir and tube) of nitrogen gas at $6.895 \mathrm{MPa}$ and $37.8^{\circ} \mathrm{C}$ being exposed to an atmospheric back pressure at $\mathrm{t}=0$.

The blowdown rates are shown in Fig. 21 for the friction and nofriction cases. Again, the effect of friction is to retard the flow.

Figure 22 depicts the steady-state solution with friction, showing the gradients along the tube similar to the Fanno-line solutions. 


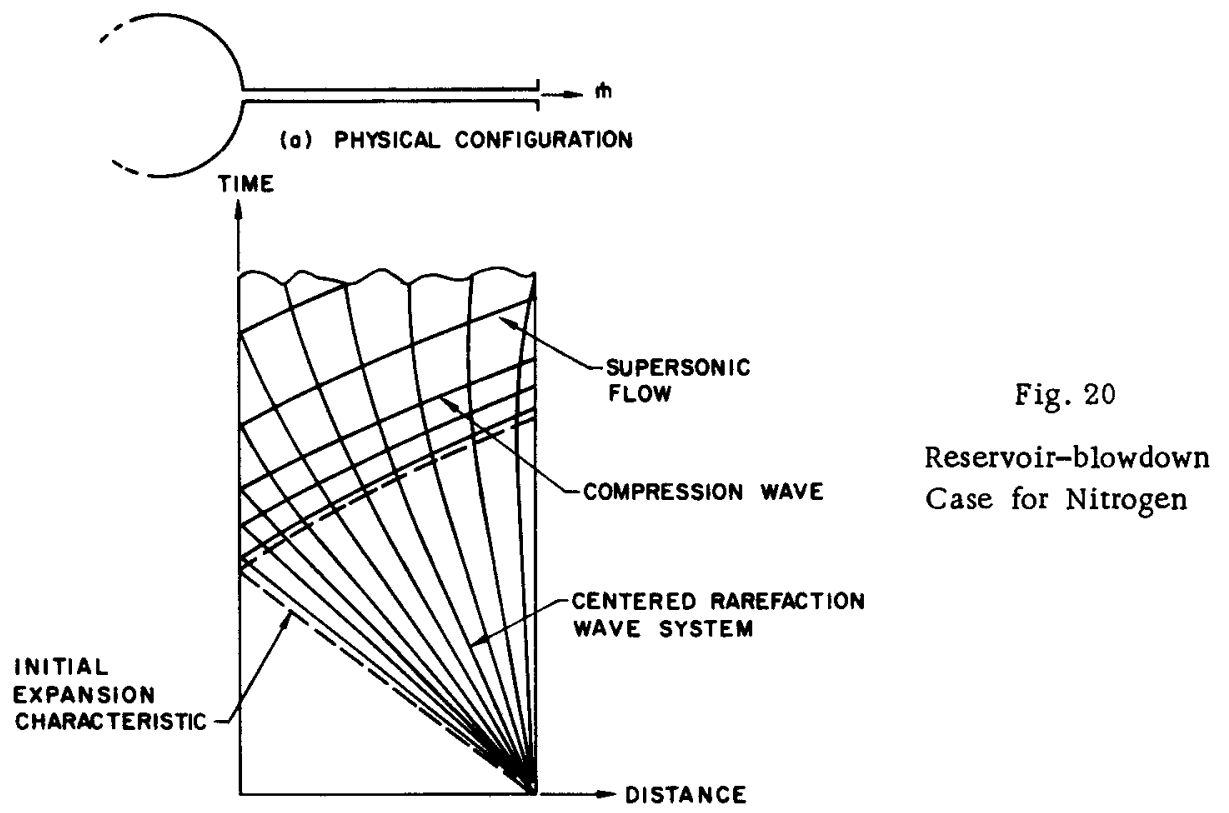

(b) WAVE DIAGRAM

Fig. 21

Mass-flow-rate History for Reservoir Blowdown of Nitrogen
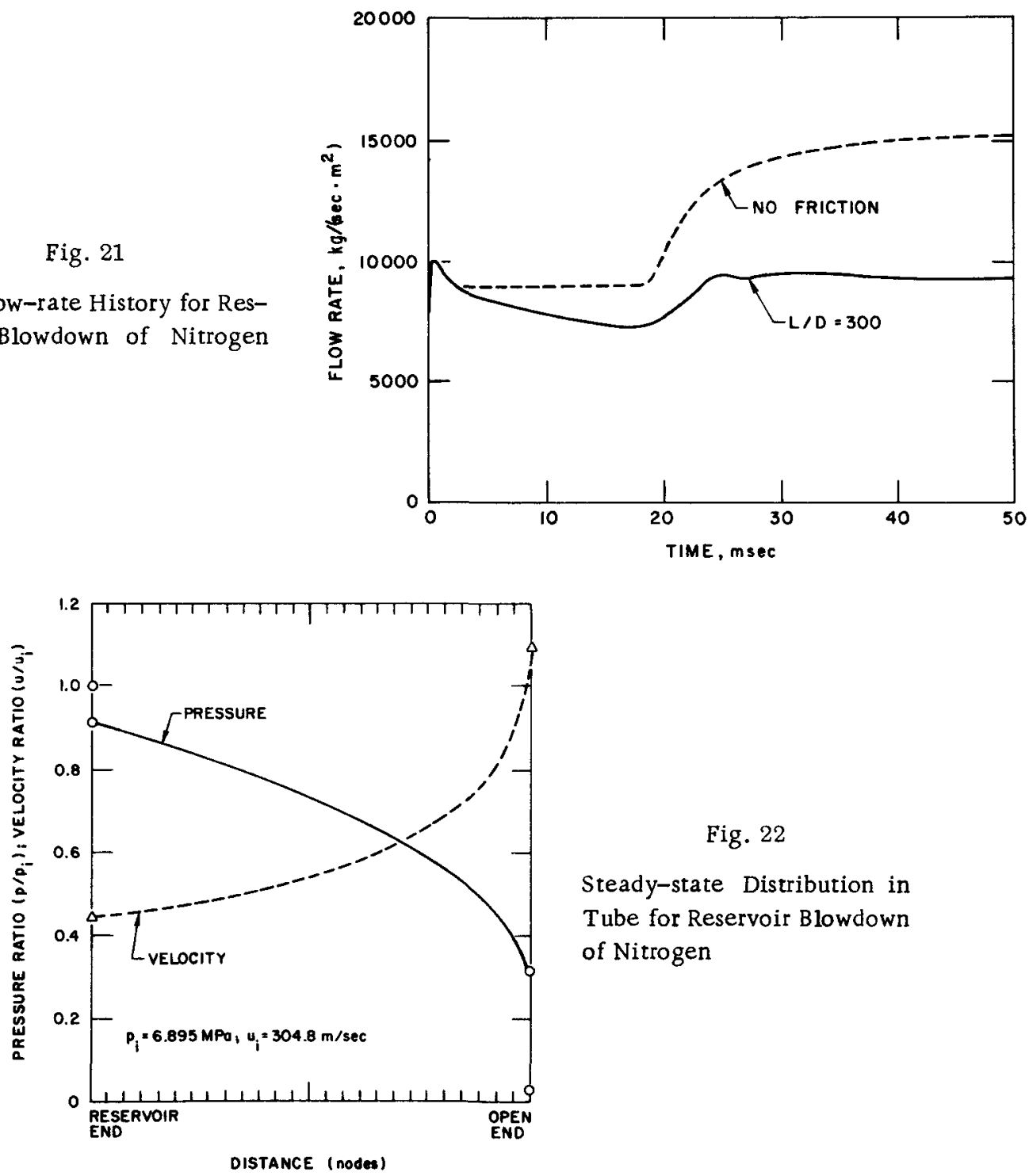

Fig. 22

Steady-state Distribution in Tube for Reservoir Blowdown of Nitrogen 


\section{DISCUSSIONS AND CONCLUSION}

The new numerical procedure presented in this report overcomes all difficulties encountered in earlier attempts noted in the literature. The procedure developed for the boundary types considered yields results in excellent agreement with reference solutions obtained by an independent method. The reference solutions were obtained by use of such a fine mesh of characteristics that the results may be regarded virtually exact.

In view of the excellent accuracy generally observed in the comparison, both the interior and boundary formulations are concluded to be an accurate method for computing transient, homogeneous, equilibrium flows. Formulations for other types of boundaries should be straightforward and may be developed by following basically the same procedures discussed in this report. An effort is under way to include other boundary types commonly encountered in typical piping networks.

The small discrepancy (typically, a few percent) observed during the starting transient is related to the mesh resolution in the finite-difference grid. Although the error is small and rather unimportant for all practical applications, control of the error is still desirable. Use of finer meshes in regions sensitive to the errors should minimize such errors. 


\section{APPENDIX \\ Derivation of Characteristic Equations}

The set of governing equations written in an expanded form is

$$
\begin{aligned}
& \frac{\partial \rho}{\partial t}+u \frac{\partial \rho}{\partial x}+\rho \frac{\partial u}{\partial x}=0, \\
& \rho\left(\frac{\partial u}{\partial t}+u \frac{\partial u}{\partial x}\right)+\frac{\partial p}{\partial x}=\rho g \cos \theta-\tau,
\end{aligned}
$$

and

$$
\rho\left(\frac{\partial \dot{i}}{\partial t}+u \frac{\partial \dot{i}}{\partial x}\right)+p \frac{\partial u}{\partial x}=u \tau+Q .
$$

It is desirable to rewrite the se equations in terms of the desired set of dependent variables, namely, p, s, and u. To do this, Eqs. A. 1 and A.3 are combined, using

$$
d i=T d s+\frac{p}{\rho^{2}} d \rho
$$

to yield the first desired equation,

$$
\frac{\mathrm{ds}}{\partial \mathrm{t}}+\mathrm{u} \frac{\partial \mathrm{s}}{\partial \mathrm{x}}=\frac{\mathrm{l}}{\rho \mathrm{T}}(\mathrm{u} \tau+\mathrm{Q}) .
$$

Equation A.5 is the particle-path equation.

A second equation is obtained by combining Eqs. A.1 and A. 5:

$$
\frac{\partial p}{\partial t}+u \frac{\partial p}{\partial x}+\rho c^{2} \frac{\partial u}{\partial x}=\frac{1}{\rho}\left(\frac{\partial p}{\partial i}\right)_{p}(u \tau+Q),
$$

where the following thermodynamic relationship is used:

$$
\left(\frac{\partial p}{\partial p}\right)_{i}=c^{2}-\frac{p}{\rho^{2}}\left(\frac{\partial p}{\partial i}\right)_{p} .
$$

A set of three characteristic equations is sought in the following which are merely linear combinations of Eqs. A.2, A.5, and A.6. Equation A.5 is already a characteristic equation; hence, only Eqs. A.2 and A. 6 are combined: 


$$
\begin{gathered}
\alpha_{1}\left[\rho\left(\frac{\partial u}{\partial t}+u \frac{\partial u}{\partial x}\right)+\frac{\partial p}{\partial x}\right]+\alpha_{2}\left(\frac{\partial p}{\partial t}+u \frac{\partial p}{\partial x}+\rho c^{2} \frac{\partial u}{\partial x}\right) \\
=\alpha_{1}(\rho g \cos \theta-\tau)+\alpha_{2} \frac{1}{\rho}\left(\frac{\partial p}{\partial i}\right)_{\rho}(u \tau+Q)
\end{gathered}
$$

This equation can be rearranged to show the respective gradients of variables:

$$
\begin{gathered}
\alpha_{2} \frac{\partial p}{\partial t}+\left(\alpha_{1}+u \alpha_{2}\right) \frac{\partial p}{\partial x}+p \alpha_{1} \frac{\partial u}{\partial t}+\rho\left(u \alpha_{1}+c^{2} \alpha_{2}\right) \frac{\partial u}{\partial x} \\
=\alpha_{1}(\rho g \cos \theta-\tau)+\alpha_{2} \frac{1}{\rho}\left(\frac{\partial p}{\partial i}\right)_{p}(u \tau+Q) .
\end{gathered}
$$

The vector $\vec{\lambda}$ normal to the characteristic in the $x-t$ plane having components $\lambda_{1}$ and $\lambda_{2}$ in the $t$ and $x$ coordinates, respectively, must satisfy the conditions

$$
\alpha_{2} \lambda_{1}+\left(\alpha_{1}+\mathrm{u} \alpha_{2}\right) \lambda_{2}=0
$$

and

$$
\rho \alpha_{1} \lambda_{1}+\rho\left(u \alpha_{1}+c^{2} \alpha_{2}\right) \lambda_{2}=0 \text {. }
$$

These are homogeneous equations in $\alpha_{1}$ and $\alpha_{2}$; hence, their determinant must vanish:

$$
\left|\begin{array}{ll}
\lambda_{2} & \lambda_{1}+u \lambda_{2} \\
\lambda_{1}+u \lambda_{2} & c^{2} \lambda_{2}
\end{array}\right|=0
$$

The solution to Eq. A. 11 is substituted in Eq. A. 10 to evaluate the $\alpha$ terms. Substitution of these values in Eq. A. 9 finally yields the characteristic equations being sought,

$$
\frac{\partial p}{\partial t}+(u+c) \frac{\partial p}{\partial x}+\rho c\left[\frac{\partial u}{\partial t}+(u+c) \frac{\partial u}{\partial x}\right]=\frac{1}{\rho}\left(\frac{\partial p}{\partial i}\right)_{p}(u \tau+Q)+c(\rho g \cos \theta-\tau)
$$

and

$$
\frac{\partial p}{\partial t}+(u-c) \frac{\partial p}{\partial x}-\rho c\left[\frac{\partial u}{\partial t}+(u-c) \frac{\partial u}{\partial x}\right]=\frac{1}{\rho}\left(\frac{\partial p}{\partial i}\right)_{\rho}(u \tau+Q)-c(\rho g \cos \theta-\tau) .
$$




\section{ACKNOW LEDGMENT}

We acknowledge James G. Daley of Components Technology Division for his assistance on use and modification of the steam-table program.

\section{REFERENCES}

1. N. G. Galluzzo, "Unsteady Water Injection Models for Analysis of Sodium/ Water Reactions in Steam Generators," ASME Paper No. 75-PVP-67, Second National Congress on Pressure Vessels and Piping, San Francisco, CA (June 1975).

2. G. F. Berry and J. G. Daley, "Pressure Transient Analysis in Single and Two-Phase Water by Finite Difference Methods," Paper No. B 2/8, Trans. 4th Int. Conf. on Structural Mechanics in Reactor Technology, San Francisco, CA (Aug 1977).

3. R. W. Lyczkowski, R. A. Grimesey, and C. W. Solbrig, "Pipe Blowdown Analyses Using Explicit Numerical Schemes," 15th National Heat Transfer Conf., San Francisco, CA (Aug 1975).

4. A. R. Edwards and T. P. O'Brien, Studies of Phenomena Connected with the Depressurization of Water Reactors, J. BNES 9, 125-135 (1970).

5. R. D. Richtmyer, A Survey of Difference Methods for Non-Steady Fluid Dynamics, National Center for Atmospheric Research Technical Note 63.2 (1963).

6. J. G. Daley, Equation of State for Steam Based on the 1968 IFC Formulation for Scientific and General Use, ANL-CT-75-16 (Nov 1974).

7. J. H. Keenan et al., Steam Tables, John Wiley and Sons, N.Y. (1969). 
Distribution for ANL-79-70

Internal:
J. A. Kyger
C. Wang
R. Avery
H. U. Ahmed
Y. Chang
L. Burris
D. H. Cho
D. M. France
D. W. Cissel
E. D. Doss
J. J. Lorenz
S. A. Davis
K. E. Kasza
B. Boers
B. R. T. Frost
C. K. Young dahl (5)
M. R. Pamidi
E. V. Krivanec
C. A. Kot
C. I. Yang
R. J. Teunis
H. C. Lin
C. E. Till
B. J. Hsieh
R. S. Zeno
M. G. Srinivasan
T. T. Yeh
J. C. M. Leung
P. S. Chopra
H. K. Fauske
J. G. Daley
W. L. Chen
S. Fistedis
G. F. Berry
D. C. C. $\mathrm{Ma}$
J. F. Marchaterre
K. D. Kuczen
P. A. Howard
G. S. Rosenberg
K. H. Im
P. R. Huebotter
M. Ishii
R. A. Valentin (2)
W. T. Sha
Y. W. Shin (34)
H. M. Domanus
M. R. Sims
S. S. Chen
A. B. Krisciunas ANL Contract File
T. Bump ANL Libraries (5) TIS Files (6)

\section{External:}

DOE-TIC, for distribution per UC-79h and -79p (228)

Manager, Chicago Operations and Regional Office, DOE

Chief, Office of Patent Counsel, DOE-CORO

Director, Technology Management, DOE-CORO

N. Bulut, DOE-CORO

Director, DOE-RRT (2)

President, Argonne Universities Association

Components Technology Division Review Committee:

D. Berg, Carnegie-Mellon U.

F. W. Buckman, Consumers Power Co.

P. F. Cunniff, U. Maryland

W. E. Kessler, Commonwealth Associates

C. H. Kruger, Jr., Stanford U.

A. Sesonske, Purdue U.

M. A. Schultz, Pennsylvania State U.

H. Thielsch, ITT Grinnell Corp.

Y. C. L. S. Wu, U. Tennessee Space Inst. 